ARTICLE

https://doi.org/10.1038/s41467-019-14237-4

\title{
Efficient electron transmission in covalent organic framework nanosheets for highly active electrocatalytic carbon dioxide reduction
}

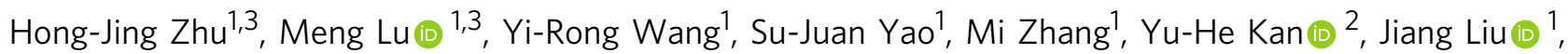
Yifa Chen ${ }^{1}$, Shun-Li Li \& Ya-Qian Lan (1) ${ }^{1 *}$

Efficient conversion of carbon dioxide $\left(\mathrm{CO}_{2}\right)$ into value-added products is essential for clean energy research. Design of stable, selective, and powerful electrocatalysts for $\mathrm{CO}_{2}$ reduction reaction $\left(\mathrm{CO}_{2} \mathrm{RR}\right)$ is highly desirable yet largely unmet. In this work, a series of metalloporphyrin-tetrathiafulvalene based covalent organic frameworks (M-TTCOFs) are designed. Tetrathiafulvalene, serving as electron donator or carrier, can construct an oriented electron transmission pathway with metalloporphyrin. Thus-obtained M-TTCOFs can serve as electrocatalysts with high $\mathrm{FE}_{\mathrm{CO}}(91.3 \%,-0.7 \mathrm{~V})$ and possess high cycling stability $(>40 \mathrm{~h})$. In addition, after exfoliation, the $\mathrm{FE}_{\mathrm{CO}}$ value of Co-TTCOF nanosheets $(\sim 5 \mathrm{~nm})$ is higher than $90 \%$ in a wide potential range from -0.6 to $-0.9 \mathrm{~V}$ and the maximum $\mathrm{FE}_{\mathrm{CO}}$ can reach up to almost $100 \%(99.7 \%,-0.8 \mathrm{~V})$. The electrocatalytic $\mathrm{CO}_{2} \mathrm{RR}$ mechanisms are discussed and revealed by density functional theory calculations. This work paves a new way in exploring porous crystalline materials in electrocatalytic $\mathrm{CO}_{2} \mathrm{RR}$.

\footnotetext{
${ }^{1}$ Jiangsu Collaborative Innovation Centre of Biomedical Functional Materials, Jiangsu Key Laboratory of New Power Batteries, School of Chemistry and Materials Science, Nanjing Normal University, Nanjing 210023, China. ${ }^{2}$ Jiangsu Province Key Laboratory for Chemistry of Low-Dimensional Materials, School of Chemistry and Chemical Engineering, Huaiyin Normal University, Huai'an 223300, China. ${ }^{3}$ These authors contributed equally: Hong-Jing Zhu, Meng Lu. *email: yqlan@njnu.edu.cn
} 
E xcessive utilization of fossil fuels and continuous human activity have led to the depletion of resources, energy crises, and global warming coupling with the pollution of highlevel carbon dioxide $\left(\mathrm{CO}_{2}\right)$ ( 411 p.p.m. in 2019) $)^{1}$. The yearly increased concentration of $\mathrm{CO}_{2}$ has resulted in the rising of sea level, abnormal climate, ocean storms, and increased desertification area, etc ${ }^{2}$. To alleviate these problems, efficient conversion of $\mathrm{CO}_{2}$ into high value-added products through methods such as electrochemical $^{3}$, photochemical ${ }^{4}$, or thermochemical ${ }^{5}$ approaches are essential and urgent. Among them, electrocatalytic $\mathrm{CO}_{2}$ reduction reaction $\left(\mathrm{CO}_{2} \mathrm{RR}\right)$ with the advantages of simple devices, high environmental compatibility, and the possibility of combination with other renewable energy sources (e.g., solar or wind energy) is considered as a kind of promising and alternative strategy ${ }^{6,7}$. However, owing to the inherent thermodynamic stability of $\mathrm{CO}_{2}$ and competitive kinetically favored $\mathrm{H}_{2}$ generation reaction, electrocatalytic $\mathrm{CO}_{2} \mathrm{RR}$ generally faces drawbacks such as low reaction activity, selectivity, or electrical conductivity, which is far from meeting the demand of practical applications ${ }^{8-10}$. To conquer these problems, diverse electrocatalysts such as metals (e.g., $\mathrm{Cu}$ or $\mathrm{Fe}$, etc. $)^{11,12}$, metal dichalcogenide (e.g., $\mathrm{WSe}_{2}, \mathrm{Ag}_{2} \mathrm{~S}$ or $\mathrm{CuS}$, etc. $)^{13}$, and metal oxide (e.g., $\mathrm{Co}_{3} \mathrm{O}_{4}, \mathrm{Cu}_{2} \mathrm{O}$, or $\mathrm{SnO}_{2}$, etc. $)^{14-16}$ have been explored for electrocatalytic $\mathrm{CO}_{2} \mathrm{RR}$. Yet, despite the intensive investigation, they still face some problems such as $\mathrm{CO}_{2}$ adsorption or enrichment ability, intermolecular electron transmission efficiency, and electrocatalysis mechanism due to their non-porous or undefined structures.

Notably, porous crystalline materials such as covalent organic frameworks (COFs) with well-defined crystal structures have been explored as promising platforms in electrocatalytic $\mathrm{CO}_{2} \mathrm{RR}^{17-19}$. COFs, a class of porous crystalline materials composed of light-weight elements and connected by strong covalent bonds, possess predictable structures, high stability, and porosity $^{20-23}$. COFs serving as promising and alternative materials in electrocatalytic $\mathrm{CO}_{2} \mathrm{RR}$ are mostly attributed to the following reasons: (i) compared with other materials with higher density, COFs with similar quality might provide more exposed surface area and active sites; (ii) the tunable structures endow COFs with diverse functionality such as electron donating, transferring, or $\mathrm{CO}_{2}$ enrichment favorable for the enhancement of electrocatalytic $\mathrm{CO}_{2} \mathrm{RR}$ performances; and (iii) various metal types (e.g., $\mathrm{Co}, \mathrm{Cu}$, and $\mathrm{Ni}$, etc.) can be modified into their structures to impart COFs with tunable catalysis centers. Therefore, the syntheses of novel COFs and the exploration of them in electrocatalytic $\mathrm{CO}_{2} \mathrm{RR}$ are very meaningful and highly demanded. However, despite the promising properties of COFs in electrocatalytic $\mathrm{CO}_{2} \mathrm{RR}$, only a few works about COFs (e.g., COF-366-Co and COF-367-Co, etc.) and their derivatives (e.g., modified with functional groups such as fluorine or methoxy) have been explored ${ }^{17-19}$. Nevertheless, the electrocatalytic $\mathrm{CO}_{2} \mathrm{RR}$ efficiency of COFs are relatively low (the faradic efficiency of carbon monoxide $\left(\mathrm{FE}_{\mathrm{CO}}\right)$, generally $<$ $90 \%$ ), which might be in part attributed to the low intermolecular electron transmission efficiency or lack in oriented electron transmission pathway. Besides, closely packed two-dimensional (2D) layer structure of COFs, especially in an eclipsed stacking fashion with strong $\pi-\pi$ interactions, will inevitably lead to insufficient utilization of the active sites and result in low electrocatalysis performances ${ }^{24,25}$. Exfoliation of the layered organic structure can expose larger surface area and more accessible active sites to facilitate the contact with substrate molecules, which would serve as an effective strategy to overcome this issue ${ }^{26-28}$. Nevertheless, the exploration of exfoliated 2D COF in electrocatalytic $\mathrm{CO}_{2} \mathrm{RR}$ has not been reported. Therefore, the construction of novel COFs from functional units and further study the possibility of exfoliated COFs in efficient electrocatalytic $\mathrm{CO}_{2} \mathrm{RR}$ are highly desirable.
Tetrathiafulvalene (TTF) as a kind of electron donor with high electron mobility is able to synthesize highly conductive chargetransfer crystals when constructed with electron acceptors ${ }^{29,30}$. A well-defined TTF-based structure might have the potential for the particular alignment and stacking of TTF columns as conductive pathways $^{31}$. Metalloporphyrin, possessing conjugated $\pi$-electron system, can act as excellent electron acceptor and electron transfer carrier $3,32,33$. Combining TTF with metalloporphyrin might construct intermolecular charge-transfer pathway in a structure to largely enhance the electron transfer efficiency. Up to date, COFs that are based on only TTF or metalloporphyrin have been investigated ${ }^{34-37}$. The combination of them in a COF structure might be of high significance in electron transfer efficiency to enhance the electrocatalytic $\mathrm{CO}_{2} \mathrm{RR}$ activity.

Herein, a series of stable and high crystalline metalloporphyrinTTF based COFs (M-TTCOFs) are produced through the assembly of metallized 5,10,15,20-tetrakis (4-aminophenyl) porphinato (MTAPP, $\mathrm{M}=\mathrm{Co}$ or $\mathrm{Ni}$ ) and 2,3,6,7-tetra (4-formylphenyl)-tetrathiafulvalene (4-formyl-TTF) (Fig. 1a). The synergistic combination of metalloporphyrin and TTF can serve as the role of gathering electron donating, electron migration, and electrocatalytic active components together in these M-TTCOFs. Combining high porosity, excellent chemical stability, and uniformly distributed metal centers in the structures, thus-obtained M-TTCOFs with diverse transition metals (i.e., Co or Ni) present superior electrocatalytic $\mathrm{CO}_{2} \mathrm{RR}$ performances. Notably, Co-TTCOF is able to selectively convert $\mathrm{CO}_{2}$ to $\mathrm{CO}$ with a $\mathrm{FE}_{\mathrm{CO}}$ of $91.3 \%$ at $-0.7 \mathrm{~V}$ and possesses remarkable cycling stability $(>40 \mathrm{~h})$. Besides, after exfoliation, the $\mathrm{FE}_{\mathrm{CO}}$ of Co-TTCOF nanosheets (denoted Co-TTCOF NSs, $\sim 5 \mathrm{~nm}$ in thickness) can reach up to $99.7 \%$ at $-0.8 \mathrm{~V}$, which is highest in reported COFs. Furthermore, the electrocatalytic $\mathrm{CO}_{2} \mathrm{RR}$ mechanisms of M-TTCOFs with diverse metal centers imply that CoTTCOF exhibits the lowest activation energy for the determine step in electrocatalytic $\mathrm{CO}_{2} \mathrm{RR}$ compared with other M-TTCOFs as revealed by density functional theory (DFT) calculations, which can fully support the performances.

\section{Results}

Structure and characterization of M-TTCOFs. The crystal structures of M-TTCOFs are resolved by using powder X-ray diffraction (PXRD) measurements in conjunction with Pawley refinements and the structural simulations are performed in Materials Studio 7.0. For example, taking Co-TTCOF, CoTTCOF exhibits high crystallinity in the experimental PXRD test (Fig. 1b). The Pawley refinements reproduce the experimentally detected PXRD pattern with a negligible difference (Rp, 3.01\% and Rwp, 4.34\%), which indicates the correctness of the structure. In the PXRD pattern, the peak signals at $5.15^{\circ}$ and $5.9^{\circ}$ are assigned to the (110) and (200) facets, respectively (Supplementary Fig. 1). Meanwhile, Ni-TTCOF and $\mathrm{H}_{2}$-TTCOF show intact topology with similar PXRD patterns as Co-TTCOF (Fig. 1b). In addition, Fourier-transform infrared spectroscopy and ${ }^{13} \mathrm{C}$ solid-state nuclear magnetic resonance $\left({ }^{13} \mathrm{C}\right.$ ssNMR) measurements are conducted to support the crystal structures of M-TTCOFs. Similar peak at $1622 \mathrm{~cm}^{-1}$ in $\mathrm{H}_{2}$-TTCOF and M-TTCOFs confirms the successful formation of $\mathrm{C}=\mathrm{N}$ bond in the structures, accompanied by the diminish of $\mathrm{C}=\mathrm{O} \quad\left(1697 \mathrm{~cm}^{-1}\right) \quad$ stretching band of 4-formyl-TTF and $\mathrm{N}-\mathrm{H}\left(3324 \mathrm{~cm}^{-1}\right)$ and stretching band of 5,10,15,20-tetrakis (4-aminophenyl)-21H,23H-porphine ( $\mathrm{H}_{2}$-TAPP) (Supplementary Figs. 2 and 3 ). In ${ }^{13} \mathrm{C}$ ssNMR spectra of Co-TTCOF, the $\alpha$-pyrrolic carbon present in the porphyrin moiety shows a peak at $\sim 144.5$ p.p.m. (peak b1). The dithiole carbon presented in the TTF shows a peak at $\sim 113.8$ p.p.m. (peak d1) and the peak around $\sim 115.8$ p.p.m. (peak d2) is attributed to $\beta$-pyrrolic 

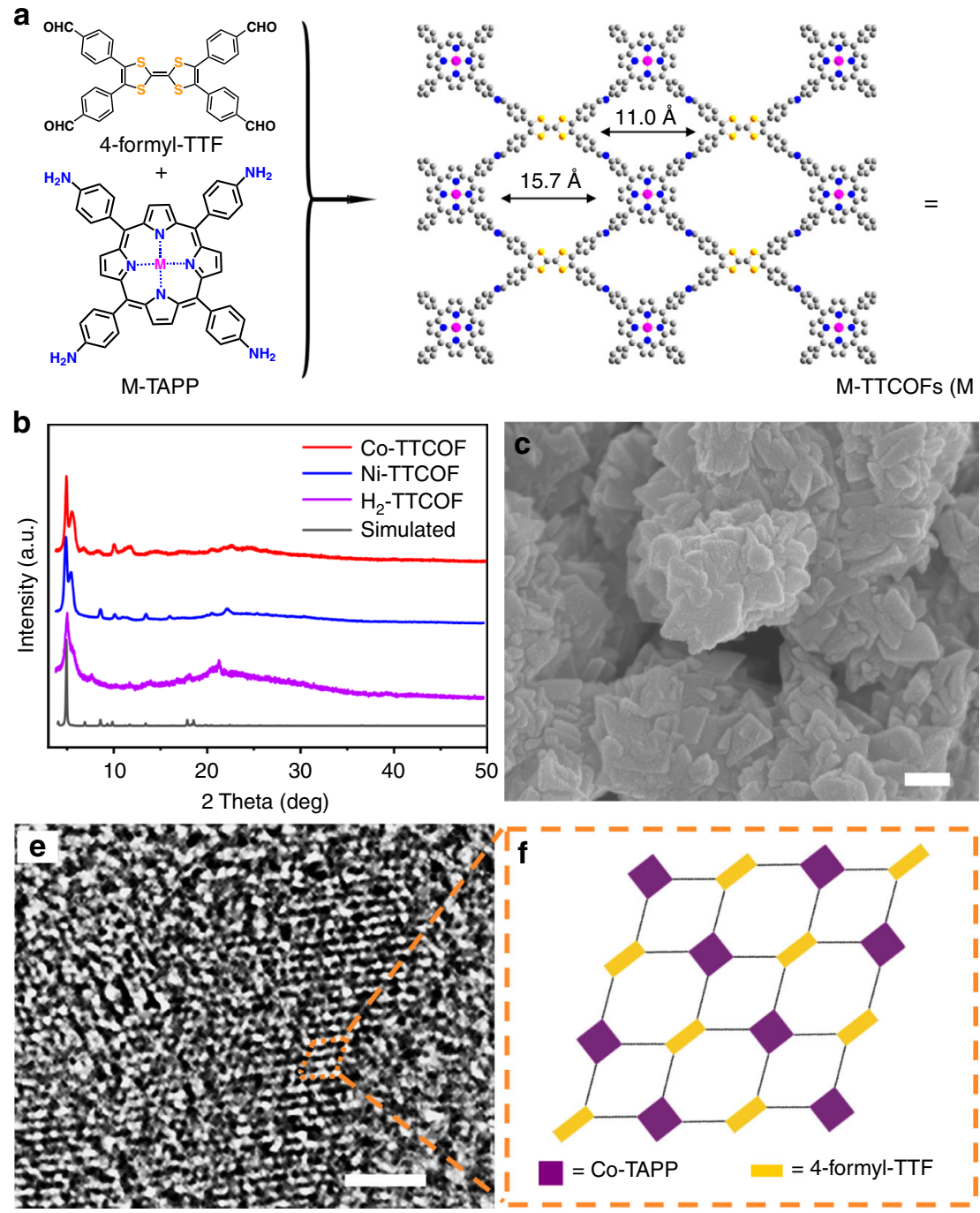

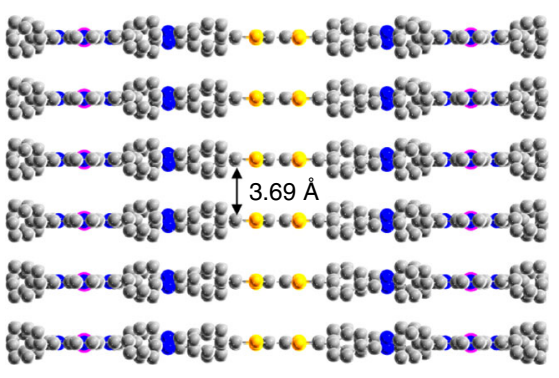

is

M-TTCOFs (M = Co or $\mathrm{Ni})$
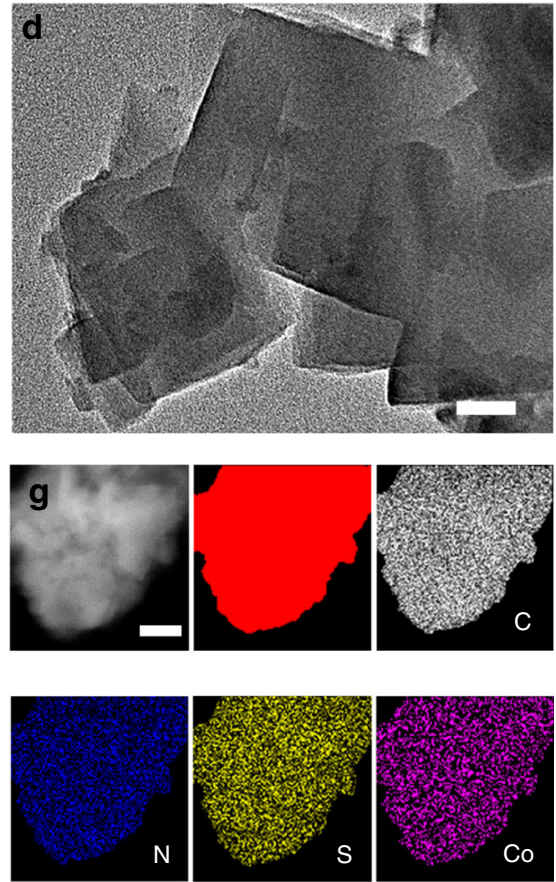

Fig. 1 Structure and characterization of $\mathbf{M}$-TTCOFs $(\mathbf{M}=\mathbf{C o}$ or $\mathbf{N i})$. a The structure of M-TTCOFs obtained through the condensation of 4 -formyl-TTF and M-TAPP. b Powder X-ray diffraction patterns of M-TTCOFs. c Scanning electron microscopy image, scale bar $=200$ nm. d Transmission electron microscopy image, scale bar $=50 \mathrm{~nm}$. e High-resolution transmission electron microscopy image, scale bar $=2 \mathrm{~nm}$. $\mathbf{f}$ The schematic pore structure of CoTTCOF. $\mathbf{g}$ Energy-dispersive X-ray spectroscopy elemental mapping image (the red image is the selected area in $\mathbf{g}$ ), scale bar $=100$ nm.

carbon and methine carbon of the porphyrin macrocycle (Supplementary Fig. 4d). Besides, the peaks among the range from 124 to 136 p.p.m. (peak c) can reflect the existence of phenyl moiety in Co-TTCOF. Furthermore, the formation of $\mathrm{C}=\mathrm{N}$ bond in Co-TTCOF is proved by the existence of resonance signal around 157.3 p.p.m. (peak a) (Supplementary Fig. 4$)^{33,38-40}$. In addition, the solid-state UV test is performed to verify the structure of Co-TTCOF (Supplementary Fig. 5). The electronic absorption spectrum of Co-TTCOF displays a solid-state broad absorption giving four maxima (Q-band, 546, 593 , and $738 \mathrm{~nm}$; sorbet band $412 \mathrm{~nm}$ ) in the visible region. The results indicate the existence of cobalt porphyrin unit in Co-TTCOF ${ }^{41}$. X-ray photoelectron spectroscopy (XPS) tests are further carried out to determine the surface electronic state and elemental composition of M-TTCOFs. The analyses show that the metal centers in $\mathrm{M}$-TTCOFs $(\mathrm{M}=\mathrm{Co}$ or $\mathrm{Ni})$ are all bivalence (Supplementary Figs. 6 and 7$)^{42}$.

In the structure, the assembly of metalloporphyrin and TTF generates 2D layer porous structure, which might be beneficial for the mass transfer of substrates and enrichment of $\mathrm{CO}_{2}$. To prove it, $\mathrm{N}_{2}$ and $\mathrm{CO}_{2}$ sorption tests are carried out. In $\mathrm{N}_{2}$ sorption test, the surface area of Co-TTCOF is calculated to be $481 \mathrm{~m}^{2} \mathrm{~g}^{-1}$, which is slightly lower than that of $\mathrm{H}_{2}$-TTCOF $\left(\mathrm{S}_{\mathrm{BET}}, 675 \mathrm{~m}^{2} \mathrm{~g}^{-1}\right)$ without metal doping (Supplementary Figs. 8 and 9). The pore volume of Co-TTCOF $\left(V_{t}, 0.633 \mathrm{~cm}^{3} \mathrm{~g}^{-1}\right)$ is slightly increased compared with $\mathrm{H}_{2}$-TTCOF $\left(V_{\mathrm{t}}, \quad 0.612 \mathrm{~cm}^{3} \mathrm{~g}^{-1}\right)$. For Ni-TTCOF, the surface area and pore volume are calculated to be $531 \mathrm{~m}^{2} \mathrm{~g}^{-1}$ and $0.483 \mathrm{~cm}^{3} \mathrm{~g}^{-1}$, respectively (Supplementary Fig. 10). Furthermore, $\mathrm{CO}_{2}$ adsorption capacity of Co-TTCOF is measured to be $20 \mathrm{~cm}^{3} \mathrm{~g}^{-1}$ at $293 \mathrm{~K}$ (Supplementary Fig. 11). The value is higher than that of $\mathrm{H}_{2}$-TTCOF $\left(293 \mathrm{~K}, 11 \mathrm{~cm}^{3} \mathrm{~g}^{-1}\right)$, which indicates that the doping of $\mathrm{Co}$ can enhance the adsorption capacity of $\mathrm{CO}_{2}$. Similar results that metal doping can increase the adsorption capacity are also detected for Ni-TTCOF $\left(293 \mathrm{~K}, 21 \mathrm{~cm}^{3} \mathrm{~g}^{-1}\right)$ when compared with $\mathrm{H}_{2}$-TTCOF $\left(293 \mathrm{~K}, 11 \mathrm{~cm}^{3} \mathrm{~g}^{-1}\right)$ (Supplementary Fig. 11).

The morphology of the M-TTCOFs are characterized by scanning electron microscopy (SEM) and transmission electron microscopy (TEM) tests. Taking Co-TTCOF for instance, SEM test shows that the morphology of Co-TTCOF is rectangular crystal with size about $150 \mathrm{~nm}$, which is different from that of $\mathrm{H}_{2}$-TTCOF (nanoparticle, about $100 \mathrm{~nm}$ ) (Fig. 1c and Supplementary Fig. 12). The morphology is also supported by the TEM test (Fig. 1d). Besides, high-resolution TEM (HR-TEM) exhibits that Co-TTCOF displays highly ordered pore channels, which matches well with 
the AA-stacking mode of the 2D Co-TTCOF (Fig. 1e, f) ${ }^{43,44}$. Energy-dispersive X-ray spectroscopy (EDS) mapping (Fig. 1g) analysis reveals that $\mathrm{C}, \mathrm{N}, \mathrm{S}$, and Co are uniformly distributed in Co-TTCOF nanocrystals (Supplementary Fig. 13). The total Co content in Co-TTCOF is determined to be $3.4 \mathrm{wt} \%$ by inductively coupled plasma optical emission spectrometry (ICP-OES) (Supplementary Table 1). In comparison, the morphology of Ni-TTCOF is nanopellet with a size of about $1.4 \mu \mathrm{m}$ proved by SEM and TEM tests (Supplementary Figs. 14 and 15).

Stability is a key factor to evaluate the durability of the catalysts in various applications ${ }^{45}$. To investigate the chemical stability of $\mathrm{M}$ TTCOFs, the samples of M-TTCOFs are soaking in diverse solutions for 5 days. For example, taking Co-TTCOF, the internal structure of Co-TTCOF remains intact after immersing in boiling water and $0.5 \mathrm{M} \mathrm{KHCO} 3$ (pH 7.2) for 5 days (Supplementary Fig. 16). Moreover, Co-TTCOF can be stable in $0.1 \mathrm{M} \mathrm{HCl}(\mathrm{pH} 1)$ and $0.1 \mathrm{M} \mathrm{KOH}(\mathrm{pH} \mathrm{13)}$ ) for more than 5 days (Supplementary Fig. 16). Similar results are also detected for Ni-TTCOF (Supplementary Fig. 17). Besides, TGA analyses under $\mathrm{N}_{2}$ atmosphere are conducted to evaluate the stability of these COFs (i.e., $\mathrm{H}_{2}$ TTCOF, Co-TTCOF, and Ni-TTCOF). The results indicate that these COFs can be stable up to $350^{\circ} \mathrm{C}$ (Supplementary Fig. 18). The high chemical and thermal stability of M-TTCOFs sets fundamental basis for further applications in electrocatalytic $\mathrm{CO}_{2} \mathrm{RR}$.

The electrocatalytic performances of M-TTCOFs. Above all, the specially designed M-TTCOFs constructed from TTF (electron donating unit) and metalloporphyrin (electron accepter or electron transfer unit) with highly porous structures, excellent chemical stability, and uniformly distributed metal centers might serve as promising candidates for electrocatalytic $\mathrm{CO}_{2} \mathrm{RR}$. To test their performances, M-TTCOFs (i.e., Co-TTCOF, Ni-TTCOF, and $\mathrm{H}_{2}$ TTCOF) are packaged in cells and tested in three-electrode electrochemical H-type cell with $\mathrm{CO}_{2}$ or Ar-saturated $0.5 \mathrm{M} \mathrm{KHCO}_{3}$ solution as the electrolyte. In this work, all potentials are measured using $\mathrm{Ag} / \mathrm{AgCl}$ electrode as the reference electrode and the results are reported relative to the reversible hydrogen electrode (RHE).

Linear sweep voltammetry (LSV) curves (without $i R$ compensation) show that the onset potential of Co-TTCOF $(-0.45 \mathrm{~V})$ is much more positive than that of Ni-TTCOF $(-0.64 \mathrm{~V})$ in $\mathrm{KHCO}_{3}$ solution (Fig. 2a). Tests conducted both in $\mathrm{Ar}$ and $\mathrm{CO}_{2}$ saturated $\mathrm{KHCO}_{3}$ solution show that Co-TTCOF exhibits a higher current density in $\mathrm{CO}_{2}$-saturated $\mathrm{KHCO}_{3}$ solution than that in Ar-saturated $\mathrm{KHCO}_{3}$ solution over a wide potential range $(-0.3$ to $-1.0 \mathrm{~V}$ vs. RHE), which suggests higher reaction activity of electrocatalytic $\mathrm{CO}_{2} \mathrm{RR}$ than HER (Supplementary Fig. 19). Furthermore, the gas chromatography (GC) analysis show that $\mathrm{H}_{2}$ and $\mathrm{CO}$ are the primary reduction products and there is no liquid product detected by ${ }^{1} \mathrm{H}$ NMR spectroscopy (Supplementary Fig. 20). Besides, the Tafel slope of Co-TTCOF is tested to be $237 \mathrm{mV} \mathrm{dec}^{-1}$, which is much smaller than that of Ni-TTCOF $\left(629 \mathrm{mV} \mathrm{dec}^{-1}\right)$ and $\mathrm{H}_{2}$ TTCOF (433 $\mathrm{mV} \mathrm{dec}^{-1}$ ) (Fig. 2b). This implies the more favorable kinetics of Co-TTCOF in generation of $\mathrm{CO}$, which might be ascribed to the more efficient charge-transfer ability and larger active surface during the reaction process.

To probe the electrocatalytic kinetics on the electrode/electrolyte surface, electrochemical impedance spectroscopy (EIS) measurement is carried out. Interestingly, the Nyquist plots demonstrate that Co-TTCOF has much smaller charge-transfer resistance (23.4 $\Omega)$ than Ni-TTCOF $(191.5 \Omega)$ and $\mathrm{H}_{2}$-TTCOF $(111.9 \Omega)$ during the electrocatalytic $\mathrm{CO}_{2} \mathrm{RR}$ (Supplementary Fig. 21). It implies faster electron transfer from the catalyst surface to the reactant (i.e., $\mathrm{CO}_{2}$ ) in intermediate $\left(\mathrm{HCOO}^{*}\right.$ and $\mathrm{CO}^{*}$ ) generation, thus eventually resulting in largely enhanced activity and selectivity for Co-TTCOF. To estimate the electrochemical active surface area (ECSA) and further to discuss the potential influence factors, electrochemical double-layer capacitance $\left(C_{d l}\right)$ is calculated (Supplementary Fig. 22). The obtained results show that Co-TTCOF presents a $C_{d l}$ value of $6.00 \mathrm{mF} \mathrm{cm}^{-2}$, which is higher than Ni-TTCOF $\left(3.87 \mathrm{mF} \mathrm{cm}^{-2}\right)$ and $\mathrm{H}_{2}$-TTCOF $\left(4.27 \mathrm{mF} \mathrm{cm}^{-2}\right)$. To calculate the percent of electrochemically active cobalt, cyclic voltammetry $(\mathrm{CV})$ tests of Co-TTCOF and Ni-TTCOF are conducted. Peak current and scan rate as two important parameters are detected to reveal the percent of electrochemically active sites. The peak current curve shows a linear dependence on the scan rate (tested from 20 to $120 \mathrm{mV} \mathrm{s}^{-1}$ ) for Co-TTCOF (Supplementary Fig. 23). Regression of the linear regime between 20 and $100 \mathrm{mV} \mathrm{s}^{-1}$ with equation: slope $=$ $n^{2} F^{2} \mathrm{~A} \tau_{\mathrm{o}} / 4 \mathrm{RT}$ gives the surface concentrations $\left(\tau_{\mathrm{o}}\right)$ of electroactive Co-TTCOF to be $7.05 \times 10^{-9} 17,41$. Based on the results, the percent of electrochemically active cobalt is calculated to be $0.90 \%$ for Co-TTCOF.

To further confirm the structure superiority in electrocatalytic $\mathrm{CO}_{2} \mathrm{RR}$ of the obtained M-TTTCOFs over other COF structures such as COF-366- $\mathrm{H}_{2}$ (constructed from 1,4-benzenedicarboxaldehyde and metalloporphyrin), relatively direct current conductivity tests are performed (Supplementary Fig. 24) ${ }^{17}$. Specially, $\mathrm{H}_{2-}$ TTCOF presents larger slope $(1 / \mathrm{R})$ value than $\mathrm{COF}-366-\mathrm{H}_{2}$, which indicates the synergistic effect of metalloporphyrin and TTF in creating oriented electron pathway. In this work, metallated porphyrin is mostly possible to be an electron acceptor when coupling with strong donating component such as TTF. To prove it, we have performed related $\mathrm{CV}$ and optical tests to reveal the relative energy levels (i.e., lowest unoccupied molecular orbital (LUMO) and highest occupied molecular orbital (HOMO)) of monomers and presented a detailed discussion about donor-acceptor concept (Supplementary Figs. 25-27). The HOMO levels are calculated from the onset of the first oxidation waves (i.e., 5,10,15,20-tetrakis (para-aminophenyl) porphyrin Cobalt (II) (Co-TAPP), $E^{\mathrm{OX}}=$ $0.69 \mathrm{~V}$ and 4 -formyl-TTF, $E^{\mathrm{OX}}=0.48 \mathrm{~V}$ ) from CV tests. The band gaps estimated from Tauc plot of solid-state UV show the Eg (band gaps) for Co-TAPP and 4-formyl-TTF are 1.70 and $1.63 \mathrm{eV}$, respectively (Supplementary Fig. 26b, d). The relative positions of LUMO and HOMO are obtained according to the formula $\left(\mathrm{HOMO}=-\left[\left(\mathrm{eE}^{\mathrm{OX}}-\mathrm{eE}\left(\mathrm{Fc}_{\mathrm{Fc}} \mathrm{Fc}^{+}\right)+4.8 \mathrm{~V}\right)\right] \mathrm{eV}, \mathrm{LUMO}=\right.$ $\mathrm{HOMO}-\mathrm{Eg}$ ). Based on first oxidation waves data, 4-formyl-TTF is a better electron donor as indicated by its lower oxidation potential $\left(0.48 \mathrm{~V}\right.$ vs. $\mathrm{Ag} / \mathrm{AgCl}$ in $\left.\mathrm{CH}_{3} \mathrm{CN}\right)$ than $\mathrm{Co}-\mathrm{TAPP}(0.69 \mathrm{~V}$ vs. $\mathrm{Ag} / \mathrm{AgCl}$ in $\left.\mathrm{CH}_{3} \mathrm{CN}\right)$. Further supported by the LUMO levels of Co-TAPP and 4-formyl-TTF, in which the LUMO of 4-formyl-TTF possesses higher potential $(-3.30 \mathrm{eV})$ than Co-TAPP $(-3.14 \mathrm{eV})$, which is sufficient to realize the electron transfer from 4-formylTTF to Co-TAPP (Supplementary Fig. 27). To further prove it, the comparison of Co-TAPP and Co-TTCOF in XPS tests reveals an apparent change of binding energy, which also provides a direct evidence that the charge carrier migration pathway might be from TTF to Co-TAPP (Supplementary Fig. 28) ${ }^{46}$.

To determine the carbon source of $\mathrm{CO}$, an isotopic experiment that using ${ }^{13} \mathrm{CO}_{2}$ as substrate is performed under identical reaction conditions. The products are analyzed by GC and mass spectra. As presented in Fig. $2 \mathrm{f}$, the peak at $m / z=29$ is assigned to ${ }^{13} \mathrm{CO}$, demonstrating that the carbon source of $\mathrm{CO}$ indeed derives from the $\mathrm{CO}_{2}$ used. Under the condition that Ar-saturated $\mathrm{KHCO}_{3}$ solution applied as the electrolyte, only $\mathrm{H}_{2}$ is detected by the GC (Supplementary Fig. 29). Besides, the bare carbon cloth and carbon cloth decorated with acetylene black and Nafion are measured as comparisons and no electrocatalytic $\mathrm{CO}_{2} \mathrm{RR}$ activity are detected (Supplementary Figs. 30 and 31).

Moreover, corresponding $\mathrm{FE}_{\mathrm{CO}}$ and $\mathrm{FE}_{\mathrm{H} 2}$ are calculated over the entire potential range to further evaluate the selectivity of the M-TTCOFs for electrocatalytic $\mathrm{CO}_{2} \mathrm{RR}$ (Fig. 2c). Taking 

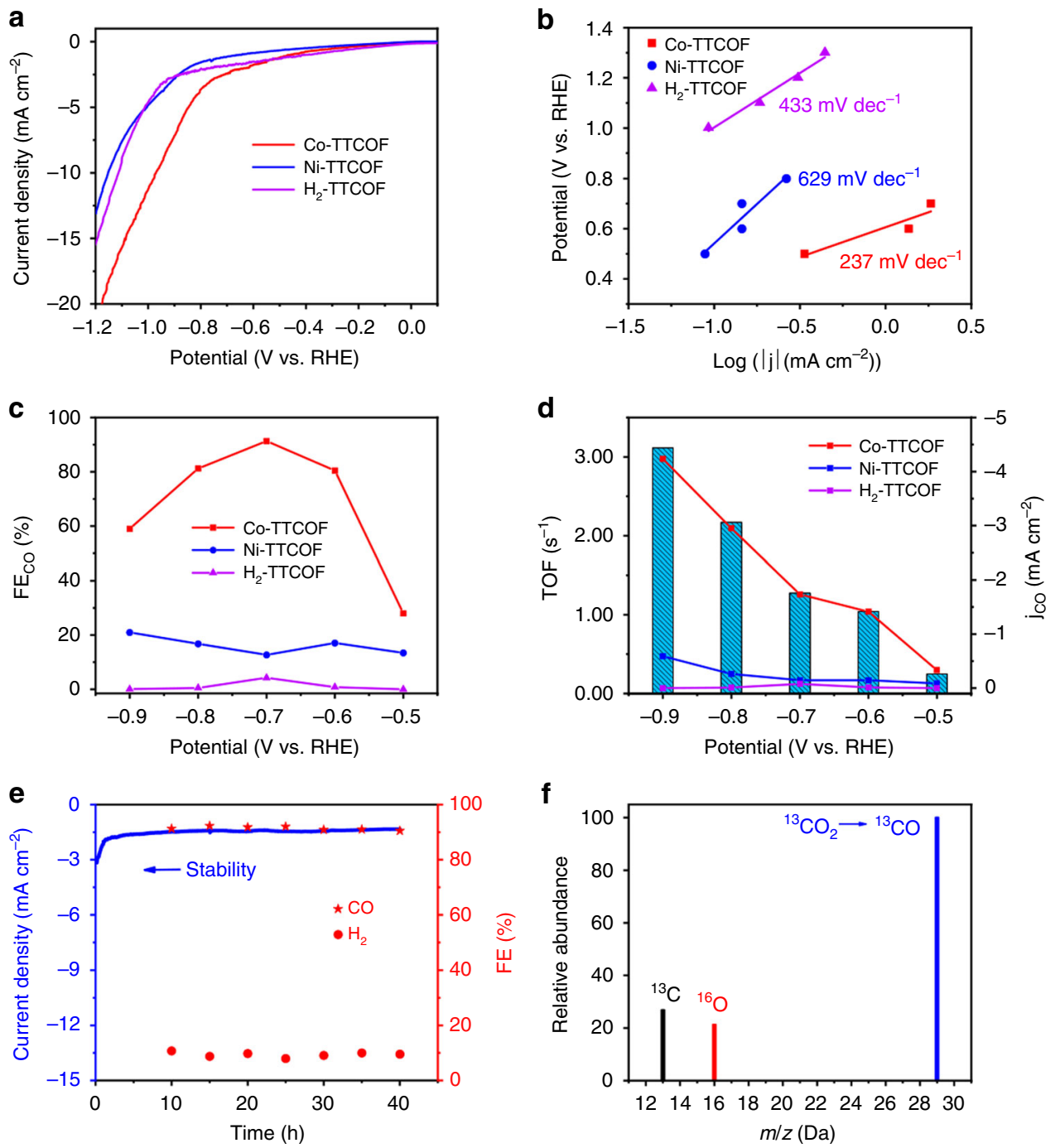

Fig. 2 Electrocatalytic performances of M-TTCOFs. a Linear sweep voltammetry curves. b Tafel plots. c The faradic efficiency of carbon monoxide calculated overpotential range from -0.5 to $-0.9 \mathrm{~V}$. d Partial CO current density and TOF $\left(\mathrm{s}^{-1}\right)$. e Cycling stability test of Co-TTCOF at the potential of $-0.7 \mathrm{~V}$ vs. RHE. $\mathbf{f}$ The mass spectra test of Co-TTCOF of ${ }^{13} \mathrm{CO}$ recorded under ${ }^{13} \mathrm{CO}_{2}$ atmosphere.

Co-TTCOF for instance, the initial formation of CO is detected by GC with a $\mathrm{CO}$ partial current density of $0.10 \mathrm{~mA} \mathrm{~cm}^{-2}$ at the potential of $-0.45 \mathrm{~V}$. With the increase of potential, the $\mathrm{FE}_{\mathrm{CO}}$ continuously enhances and reaches up to a maximum value of 91.3\% at $-0.7 \mathrm{~V}$ (Supplementary Fig. 32 and Eqs. 1 and 2). The maximum $\mathrm{FE}_{\mathrm{CO}}$ value of Co-TTCOF $(91.3 \%)$ is higher than other M-TTCOFs (i.e., Ni-TTCOF, $20.9 \%$ and $\mathrm{H}_{2}$-TTCOF, $4.22 \%$ ). Specially, the $\mathrm{FE}_{\mathrm{CO}}$ of Co-TTCOF is $\sim 32$ and 4 times higher than those of $\mathrm{H}_{2}$-TTCOF and Ni-TTCOF, respectively. Besides, CoTAPP as one of the precursors is tested as comparison and it exhibits a $\mathrm{FE}_{\mathrm{CO}}$ of $69 \%$ at $-0.9 \mathrm{~V}$ (Supplementary Fig. 33). Noteworthy, the best performance of Co-TTCOF is superior to reported COFs (e.g., COF-366-Co $\left(\mathrm{FE}_{\mathrm{CO}}, 90 \%,-0.55 \mathrm{~V}\right)$, COF$366-\mathrm{F}-\mathrm{Co}\left(\mathrm{FE}_{\mathrm{CO}}, 87 \%,-0.55 \mathrm{~V}\right)$, and $\mathrm{COF}-300-\mathrm{AR}\left(\mathrm{FE}_{\mathrm{CO}}\right.$, $80 \%,-0.55 \mathrm{~V})$ ) in electrocatalytic $\mathrm{CO}_{2} \mathrm{RR}$ (Supplementary Table 2$)^{17-19}$. To further support the remarkable performances of M-TTCOFs, partial current densities of $\mathrm{CO}$ and $\mathrm{H}_{2}$ at different potentials are detected (Fig. 2d and Supplementary Figs. 34 and 35). Co-TTCOF gives a partial CO current density of $1.84 \mathrm{~mA} \mathrm{~cm}^{-2}$ at $-0.7 \mathrm{~V}$. This value is more than ten times larger than those of Ni-TTCOF $\left(0.15 \mathrm{~mA} \mathrm{~cm}^{-2}\right)$ and $\mathrm{H}_{2}$-TTCOF $(0.079$ $\mathrm{mA} \mathrm{cm}{ }^{-2}$ ). Besides, the turnover frequency (TOF) of Co-TTCOF is calculated to be $1.28 \mathrm{~s}^{-1}$ at $-0.7 \mathrm{~V}$.
Long-time durability is an important parameter to estimate the performance in electrocatalytic $\mathrm{CO}_{2} \mathrm{RR}$, as it determines the lifetime of electrocatalysts. To study it, the $\mathrm{CO}_{2} \mathrm{RR}$ stability of CoTTCOF is performed with chronoamperometric test at a fixed potential of $-0.7 \mathrm{~V}$ in $0.5 \mathrm{M} \mathrm{KHCO}_{3}$ solution. After $40 \mathrm{~h}$, negligible decay in activity is detected (the gaseous product is analyzed by GC every $10 \mathrm{~h}$ ) (Fig. 2e). During the process, the corresponding $\mathrm{FE}_{\mathrm{CO}}$ can be retained at values $>90 \%$ over the entire experiment, which implies Co-TTCOF to be a highly stable electrocatalyst. Based on the results, the TON of Co-TTCOF is calculated for this process. Notably, the TON (CO) of Co-TTCOF is as high as 40,142 in just $10 \mathrm{~h}$ and can reach up to 141,479 after $40 \mathrm{~h}$. Besides, the TON $\left(\mathrm{H}_{2}\right)$ of Co-TTCOF is 4014 in $10 \mathrm{~h}$ and can reach up to 14,148 after $40 \mathrm{~h}$ (Supplementary Fig. 36). To evaluate the durability of Co-TTCOF, HR-TEM, SEM, and XPS tests of Co-TTCOF after electrocatalysis are performed. The SEM and TEM images of Co-TTCOF agree well with the state before electrocatalysis, indicating Co-TTCOF can maintain its morphology after electrocatalysis (Supplementary Fig. 37). Besides, the XPS tests after electrocatalysis show that the valence state of Co (II) remains almost unchanged (i.e., Co2 $\mathrm{p}_{3 / 2}, 780.86 \mathrm{eV}$ and $\mathrm{Co} 2 \mathrm{p}_{1 / 2}, 760.16 \mathrm{eV}$ ) when compared with that of Co-TTCOF (i.e., $\mathrm{Co} 2 \mathrm{p}_{3 / 2}, 780.84 \mathrm{eV}$ and $\mathrm{Co} 2 \mathrm{p}_{1 / 2}, 796.14 \mathrm{eV}$ ) before electrocatalysis 
a

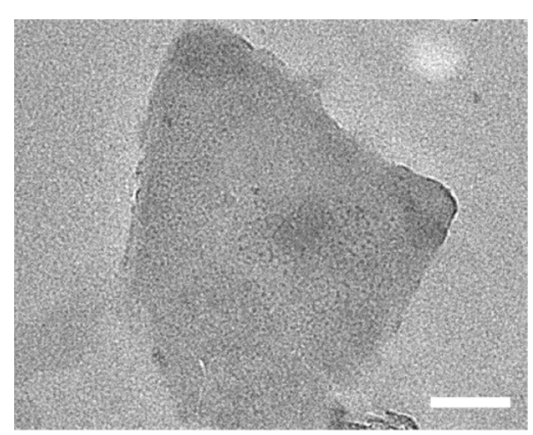

C
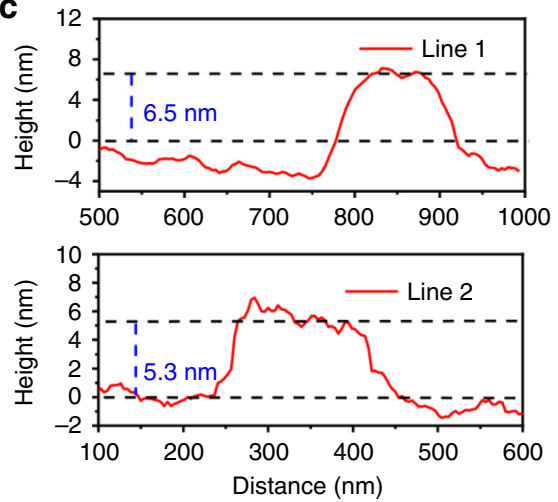

b

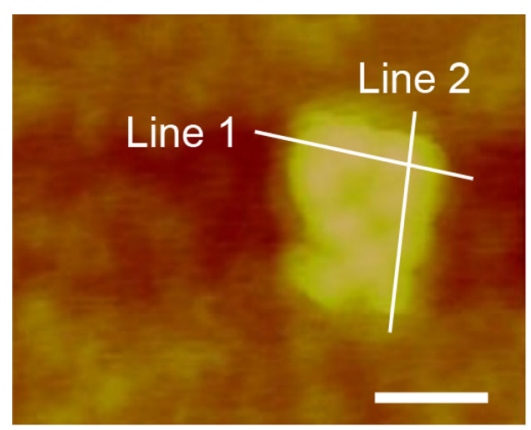

d

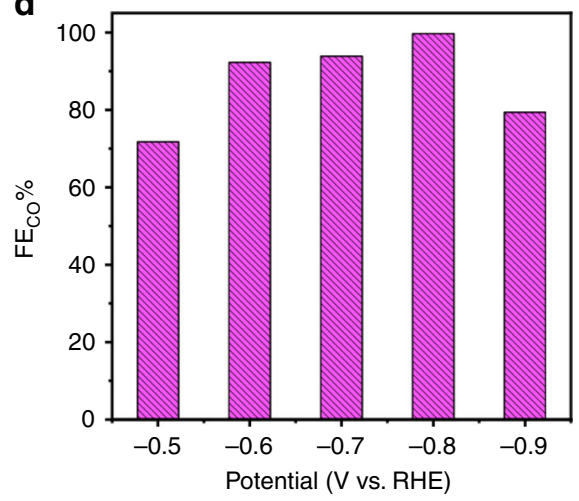

e

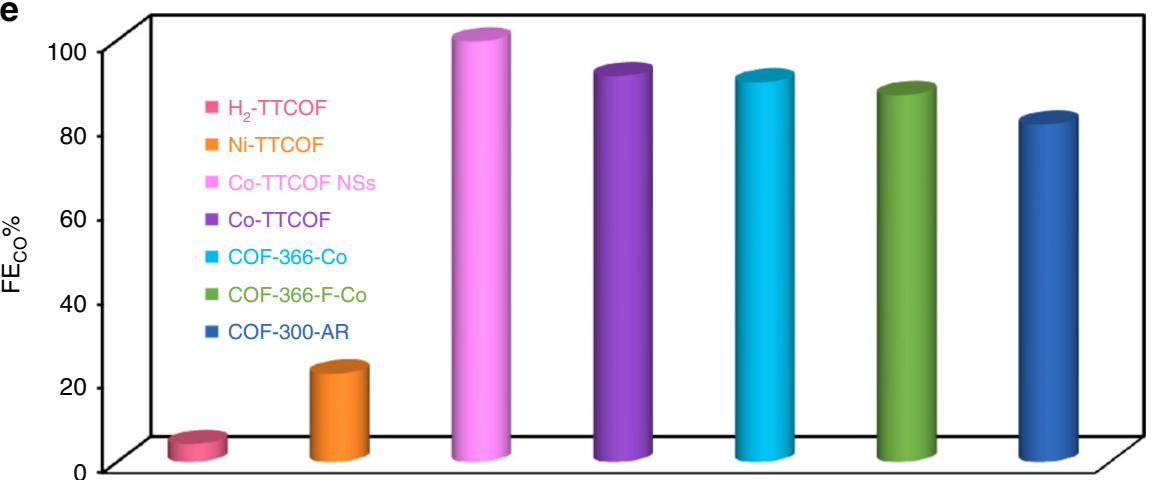

Fig. 3 Characterization and electrocatalytic performances of Co-TTCOF NSs. a TEM image, scale bar $=100 \mathrm{~nm}$. $\mathbf{b}$ The atomic force microscope topographical image, scale bar $=100 \mathrm{~nm}$. c Height profile (line 1 and 2 represent the lines in $\mathbf{b}$. $\mathbf{d}$ FE $\mathrm{E}_{\mathrm{CO}}$ of Co-TTCOF nanosheets over a potential range from -0.5 to $-0.9 \mathrm{~V}$. e A summary of electrocatalytic performances of the literature reported materials and M-TTCOFs.

(Supplementary Fig. 38). Moreover, ICP test of Co-TTCOF after long-time durability test $(>40 \mathrm{~h})$ has been conducted and negligible leaching of metal ions are detected in the electrolyte. These results indicate Co-TTCOF to be excellent electrocatalyst with high durability, which might be attributed to the strong covalent bonds generated in COFs.

In addition, we have tested the $\mathrm{pH}$ dependence of overpotential values 41,47 . After numerous trial-and-error processes, acidic electrolyte with $\mathrm{pH}$ values of $4.8,5.8$, and 6.8 are picked as three representative ones to investigate the $\mathrm{pH}$ dependence of overpotential values (Supplementary Fig. 39). LSV tests (without $i R$ compensation) and electrocatalytic $\mathrm{CO}_{2} \mathrm{RR}$ performances of $\mathrm{Co}$ TTCOF as two kinds of powerful methods are applied to reveal the $\mathrm{pH}$ dependence of overpotential values from different aspects. In LSV curves, the overpotential at $1 \mathrm{~mA} \mathrm{~cm}^{-2}$ decreases from $\sim 410 \mathrm{mV}(\mathrm{pH} 4.8)$ to $\sim 340 \mathrm{mV}$ (pH 5.8) and finally slightly increases to $\sim 350 \mathrm{mV}$ ( $\mathrm{pH}$ 6.8) with the increase of $\mathrm{pH}$ values (Supplementary Figs. 39a, b). Although for the electrocatalytic performances of Co-TTCOF, the overpotential (based on the highest $\mathrm{FE}_{\mathrm{CO}} \%$ ) of Co-TTCOF reaches to $\sim 790 \mathrm{mV}$ both for $\mathrm{pH}$ 4.8 and $\mathrm{pH} 5.8$, then the value decreases to $\sim 590 \mathrm{mV}$ (pH 6.8). The results of these two methods indicate that the overpotential value is closely related to the $\mathrm{pH}$ of electrolyte.

Based on the remarkable stability and high performances of MTTCOFs, methods that can further increase the performances of M-TTCOFs are meaningful to explore the tunability and applicability in practical applications of these porous materials. As a kind of 2D material, the potential exfoliation ability of MTTCOFs in converting bulks into nanosheets might have improvements in the performance of electrocatalytic $\mathrm{CO}_{2} \mathrm{RR}$. Herein, we report the first case of exfoliated COF in the application of electrocatalytic $\mathrm{CO}_{2} \mathrm{RR}$. By high-frequency sonication for $30 \mathrm{~min}$, the original bulk crystals are transformed into Co-TTCOF NSs with a size of $\sim 200 \mathrm{~nm}$ proved by TEM test (Fig. 3a). After exfoliation, the inert structure of Co-TTCOF remains intact in the nanosheets as certified by PXRD tests (Supplementary Fig. 40). To evaluate the thickness of the obtained Co-TTCOF NSs, atomic force microscope (AFM) tests 


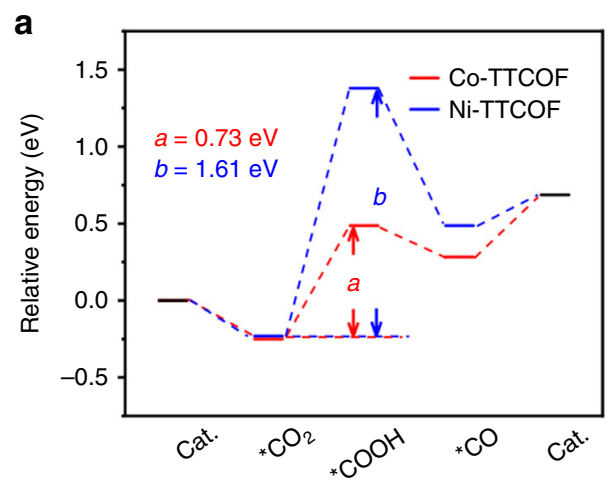

C

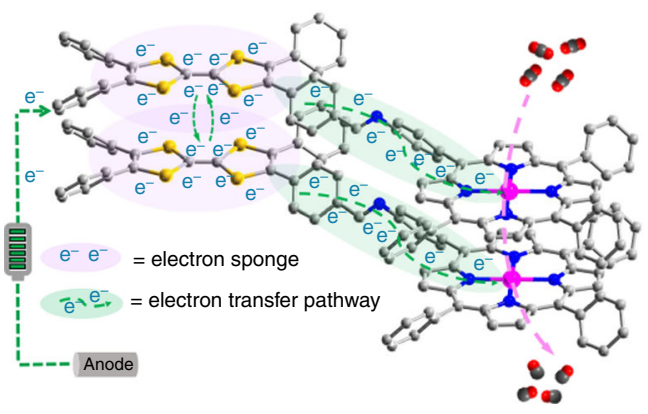

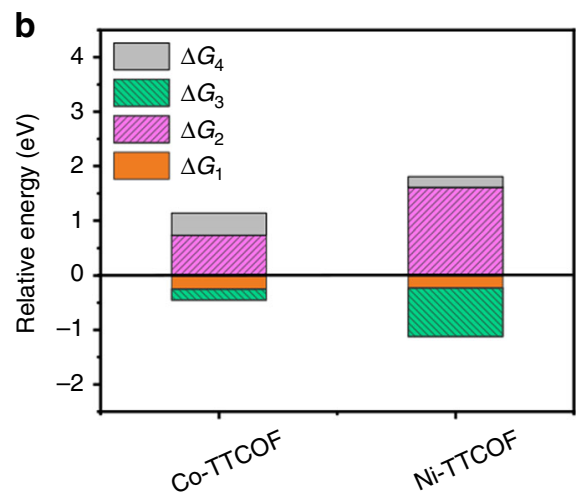

d

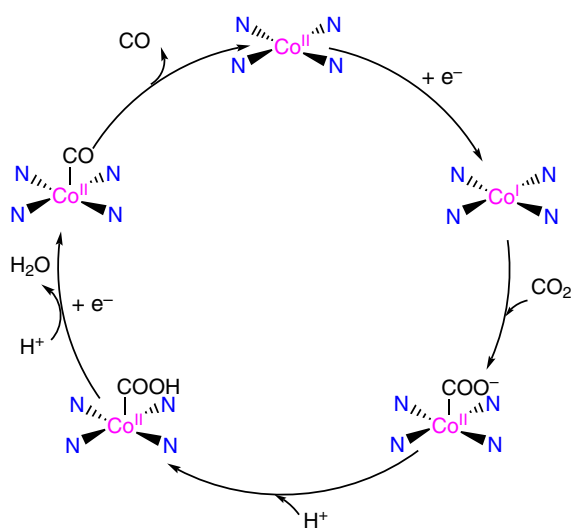

Fig. 4 DFT calculations and proposed schematic mechanism of M-TTCOFs. a The relative energy diagrams of $\mathrm{CO}_{2}$ reduction to $\mathrm{CO}$ for $\mathrm{M}$-TTCOFs $(\mathrm{M}=\mathrm{Co}$ or $\mathrm{Ni})$. $\mathbf{b}$ Comparison of the relative energy of each elementary reaction $\left(\Delta G_{1}, \Delta G_{2}\right.$, and $\Delta G_{3}$ represent the free energy of ${ }^{*} \mathrm{CO}{ }_{2}$, ${ }^{\star} \mathrm{COOH}$, and ${ }^{\star} \mathrm{CO}$ formation, respectively, and $\Delta G_{4}$ stands for the free energy of $\mathrm{CO}$ desorption process) in electrocatalytic $\mathrm{CO}_{2} \mathrm{RR}$ for $\mathrm{M}-\mathrm{TTCOFs}(\mathrm{M}=\mathrm{Co}$ or Ni). c, d Proposed schematic mechanism for the electrocatalytic $\mathrm{CO}_{2} \mathrm{RR}$ on Co-TTCOF.

are conducted. The results detected in different regions of the nanosheets show that the thickness of Co-TTCOF NSs ranges from 5 to $6 \mathrm{~nm}$ (Fig. 3b, c). To further evaluate the selectivity of the Co-TTCOF NSs for electrocatalytic $\mathrm{CO}_{2} \mathrm{RR}$, the corresponding $\mathrm{FE}_{\mathrm{CO}}$ and $\mathrm{FE}_{\mathrm{H} 2}$ are calculated over the entire potential range. Remarkably, the $\mathrm{FE}_{\mathrm{CO}}$ value is higher than $90 \%$ in a wide potential range of -0.6 to $-0.9 \mathrm{~V}$ (Fig. $3 \mathrm{~d}$ ). The maximum $\mathrm{FE}_{\mathrm{CO}}$ value $\left(\mathrm{FE}_{\mathrm{CO}}, 99.7 \%\right)$ of Co-TTCOF NSs at $-0.8 \mathrm{~V}$ is higher than unexfoliated one $\left(\mathrm{FE}_{\mathrm{CO}}, 91.3 \%\right)$. Noteworthy, the $\mathrm{FE}_{\mathrm{CO}}$ value is also highest among reported COFs (Fig. 3e) ${ }^{17-19}$.

The DFT calculation and reaction mechanism. To understand the high activity and reaction mechanism of Co-TTCOF, the DFT calculations are performed (Supplementary Note 1). In general, the electroreduction of $\mathrm{CO}_{2}$ to $\mathrm{CO}$ includes three elementary reactions, the formation of ${ }^{\star} \mathrm{COOH}$ and ${ }^{*} \mathrm{CO}$ with one electron transfer for each of them and the $\mathrm{CO}$ desorption process (Fig. 4a). The asterisk $\left(^{*}\right)$ represents the surface active sites for adsorption and reaction. When assembling TTF and metalloporphyrin together, Co-TTCOF possesses remarkably reduced $\Delta G_{2}$ (free energy for ${ }^{\star} \mathrm{COOH}$ formation in the rate-determining steps (RDS), $0.73 \mathrm{eV}$ ) and $\Delta G_{3}$ (free energy for ${ }^{\star} \mathrm{CO}$ formation, $-0.20 \mathrm{eV}$ ) compared with other M-TTCOFs, being consistent with its higher electroreduction activity and selectivity (Fig. 4a, b). For Ni-TTCOF, the RDS for the formation of ${ }^{*} \mathrm{COOH}$ become harder $\left(\Delta G_{2}, \mathrm{Ni}\right.$-TTCOF, $\left.1.61 \mathrm{eV}\right)$ when compared with Co-TTCOF (Fig. 4a, b). In a word, the results of the reaction energies for M-TTCOFs with different metal centers can fully support the experiments, which can further confirm the high activity of the Co-TTCOF.
Based on the experiment results and theoretical calculations, possible reduction processes and mechanism from $\mathrm{CO}_{2}$ to $\mathrm{CO}$ on Co-TTCOF are elaborated (Fig. 4c, d). During electrocatalytic $\mathrm{CO}_{2} \mathrm{RR}$, Co centers in Co-TTCOF are reduced from $\mathrm{Co}(\mathrm{II})$ to $\mathrm{Co}$ (I) proved by the cyclic voltammetry (CV) tests, which has been detected in many works (Supplementary Fig. 41) ) $^{3,17}$. As presented in the schematic diagram, TTF as a kind of electron sponge and donator with high electron mobility can construct efficient electron transmission pathway with metalloporphyrin (Fig. 4c). During the electrocatalytic $\mathrm{CO}_{2} \mathrm{RR}$ process, TTF initially traps the electron from the electrode and efficiently transfers it to Co center through the electron transmission pathway (Fig. 4c). Meanwhile, the Co center is reduced from Co(II) to $\mathrm{Co}(\mathrm{I})$ and then $\mathrm{Co}(\mathrm{I})$ interacts with carbon monoxide to give $\mathrm{Co}(\mathrm{II})^{*} \mathrm{COOH}$ intermediate (Fig. 4d). Finally, $\mathrm{Co}(\mathrm{II})^{*} \mathrm{COOH}$ converts to $\mathrm{Co}(\mathrm{II})$ ${ }^{\star} \mathrm{CO}$ and $\mathrm{CO}$ is desorbed (Supplementary Note 2).

\section{Discussion}

In summary, we have designed and synthesized a series of stable COFs via Schiff-base condensation reaction of metalloporphyrin and TTF. The synergistic combination of TTF and metalloporphyrin in these M-TTCOFs can serve as the role of gathering electron donating, electron migration, and electrocatalytic active components together in the electrocatalytic $\mathrm{CO}_{2} \mathrm{RR}$. Imparting with high porosity, excellent chemical stability and uniformly distributed metal centers, thus-obtained M-TTCOFs present excellent electrocatalytic $\mathrm{CO}_{2} \mathrm{RR}$ performances. Remarkably, CoTTCOF is able to selectively convert $\mathrm{CO}_{2}$ into $\mathrm{CO}$ with a $\mathrm{FE}_{\mathrm{CO}}$ of $91.3 \%$ at $-0.7 \mathrm{~V}$. Notably, after exfoliation, the $\mathrm{FE}_{\mathrm{CO}}$ of $\mathrm{Co}-$ TTCOF nanosheets ( $\sim 5 \mathrm{~nm}$ in thickness) is higher than $90 \%$ in a 
wide potential range from -0.6 to $-0.9 \mathrm{~V}$ and the maximum $\mathrm{FE}_{\mathrm{CO}}$ can reach up to almost $100 \%(99.7 \%,-0.8 \mathrm{~V})$, which might be attributed to the larger surface area and more accessible active sites. Furthermore, the electrocatalytic $\mathrm{CO}_{2} \mathrm{RR}$ mechanisms of $\mathrm{M}$ TTCOFs with diverse metal centers show that Co-TTCOF has the lowest activation energy for the determine step in electrocatalytic $\mathrm{CO}_{2} \mathrm{RR}$ compared with other M-TTCOFs, which matches well with their performances. This strategy opens great perspectives in designing novel and efficient $\mathrm{CO}_{2} \mathrm{RR}$ electrocatalysts to address $\mathrm{CO}_{2}$ problems.

\section{Materials and methods}

Synthesis of 2,3,6,7-tetra (4-formylphenyl) tetrathiafulvalene. The synthesis method of 4-formyl-TTF follows previously reported procedure with a slight modification ${ }^{48,49}$. In detail, 4-formyl-TTF (1.0 g), 4-bromobenzaldehyde (4.5 g), Pd $(\mathrm{OAc})_{2}(0.28 \mathrm{~g}), \mathrm{PtBu}_{3} \mathrm{HBF}_{4}(1.0 \mathrm{~g})$, and $\mathrm{Cs}_{2} \mathrm{CO}_{3}(5.9 \mathrm{~g})$ were added in a $100 \mathrm{~mL}$ three-neck round-bottomed flask. After purification with high-purity nitrogen gas for three times, anhydrous tetrahydrofuram (THF) $(50 \mathrm{~mL})$ was added under nitrogen atmosphere. After that, the flask was heated at $75^{\circ} \mathrm{C}$ to reflux and kept stirring for $30 \mathrm{~h}$. After cooling to room temperature, the organic compounds were extracted with $\mathrm{CHCl}_{3}(100 \mathrm{~mL})$ for three times to collect the organic phase (dark red) followed with vacuum filtration to remove the undissolved solid. Then, the obtained sample was washed with brine $(100 \mathrm{~mL})$ for three times by using a pearshaped separatory funnel and was dried with anhydrous $\mathrm{Na}_{2} \mathrm{SO}_{4}$. After that, the organic phase was collected to afford crude product (dark red) through rotary evaporation to remove the solvent. The resulted sample was purified by column chromatography with silica using dichloromethane:acetone $=500: 3$ as mobile phase to achieve pure product 4 -formyl-TTF $(0.9 \mathrm{~g})$ (red, $~ 30 \%$ yield).

\section{Synthesis of $5,10,15,20$-tetrakis (para-aminophenyl) porphyrin cobalt (II)} The synthesis method of Co-TAPP follows previously reported procedures ${ }^{17}$. In detail, $\mathrm{H}_{2}$-TAPP $(200 \mathrm{mg}, 0.3 \mathrm{mmol})$ and $\mathrm{Co}(\mathrm{OAc})_{2} \cdot 2 \mathrm{H}_{2} \mathrm{O}(212 \mathrm{mg}, 1.2 \mathrm{mmol})$ were added in a $250 \mathrm{~mL}$ three-neck round-bottomed flask. After purification with high-purity nitrogen gas for three times, a solvent mixture of methanol $(20 \mathrm{~mL})$, chloroform $(90 \mathrm{~mL})$, and $N, N^{\prime}$-dimethylformamide $(30 \mathrm{~mL})$ were added. The flask was heated at $80^{\circ} \mathrm{C}$ under stirring and nitrogen atmosphere for $24 \mathrm{~h}$. After cooling to room temperature, the solution was transferred into a separatory funnel and washed with water $(3 \times 100 \mathrm{~mL})$. After that, the solution was collected through rotary evaporation to afford dark purple solid (Co-TAPP, $\sim 180 \mathrm{mg}, \sim 85 \%$ yield).

Synthesis of Co-TTCOF. The synthesis method of Co-TTCOF follows previously reported procedures ${ }^{33}$. Co-TAPP $(14.7 \mathrm{mg}, 0.02 \mathrm{mmol}), 4$-formyl-TTF $(12.4 \mathrm{mg}$, $0.02 \mathrm{mmol}), 1,4$-dioxane $(0.5 \mathrm{~mL}), 1,3,5$-trimethylbenzene $(0.5 \mathrm{~mL})$, and $6 \mathrm{M}$ aqueous acetic acid $(0.2 \mathrm{~mL}$ ) were mixed in a Pyrex tube (outside diameter $x$ length, $19 \times 65 \mathrm{~mm}$ ). After sonication for about $15 \mathrm{~min}$, the tube was flash frozen at $77 \mathrm{~K}$ (liquid $\mathrm{N}_{2}$ bath) and degassed to achieve an internal pressure of $\sim 100 \mathrm{mTorr}$. After the temperature recovers to room temperature, the mixture was heated at $120^{\circ} \mathrm{C}$ and left undisturbed for $72 \mathrm{~h}$. After filtration, the wet sample was transferred to a Soxhlet extractor and washed with THF $(24 \mathrm{~h})$ and acetone $(24 \mathrm{~h})$. Finally, the product was evacuated at $150{ }^{\circ} \mathrm{C}$ under dynamic vacuum overnight to yield activated sample ( $28.4 \mathrm{mg}, \sim 80 \%$ yield based on Co-TAPP).

Synthesis of $\mathbf{H}_{\mathbf{2}} / \mathrm{Ni}$-TTCOF. The syntheses of $\mathrm{H}_{2} / \mathrm{Ni}$-TTCOF followed similar procedures as Co-TTCOF, except that Co-TAPP was replaced with $\mathrm{H}_{2}$-TAPP $(13.5 \mathrm{mg}, 0.02 \mathrm{mmol})$ and $\mathrm{Ni}$-TAPP $(14.7 \mathrm{mg}, 0.02 \mathrm{mmol})$, respectively.

Synthesis of Co-TTCOF NSs. Co-TTCOF bulks $(30 \mathrm{mg}$ ) were added into a beaker and then high-frequency $(1000 \mathrm{~W})$ sonication was carried out for $30 \mathrm{~min}$ with deionized water $(100 \mathrm{~mL})$ at room temperature $\left(25^{\circ} \mathrm{C}\right)$. After filtration (filter paper, $\sim 220 \mathrm{~nm}$ ), the obtained sample was collected and dried under vacuum at $60^{\circ} \mathrm{C}$ for $12 \mathrm{~h}$.

Characterizations and instruments. PXRD patterns were recorded on a $\mathrm{D} / \mathrm{max}$ $2500 \mathrm{VL} / \mathrm{PC}$ diffractometer (Japan) equipped with a graphite monochromatized $\mathrm{Cu}$ Ka radiation source $(\lambda=1.54060 \AA)$. The corresponding working voltage and current are $40 \mathrm{kV}$ and $100 \mathrm{~mA}$, respectively. TEM and HR-TEM images were recorded on JEOL-2100F apparatus at an accelerating voltage of $200 \mathrm{kV}$. Morphological and microstructural analyses were conducted using a SEM (JSM-7600F) at an accelerating voltage of $10 \mathrm{kV}$. EDS was performed with a JSM-5160LVVantage type energy spectrometer. Nitrogen adsorption-desorption isotherms were recorded at $77 \mathrm{~K}$ using a Quantachrome instrument (Quantachrome Instruments Autosorb IQ2). XPS was performed on a scanning X-ray microprobe (PHI 5000 Verasa, ULAC-PHI, Inc.) using $\mathrm{Al} \mathrm{Ka}$ radiation and the $\mathrm{C} 1 s$ peak at $284.8 \mathrm{eV}$ as the internal standard. ICP-OES (Leeman Labs) was used to measure the content of metal ions. Hydrogen amounts were analyzed using a gas chromatograph (GC7900, CEAULight, China) equipped with a thermal conductivity detector (TCD).
AFM was performed on tapping mode (Vecco Nanoscope Multimode 8.0). Converting Co-TTCOF bulks into nanosheets used ultrasonic cell grinder (VOSHIN$1000 \mathrm{~W})$. The relatively direct current conductivity tests were conducted with a probe station at room temperature $\left(25^{\circ} \mathrm{C}\right)$ under ambient conditions with a computer-controlled analog-to-digital converter (2636B, Kethley). The conductive sample was pressed into a sheet using a ton of pressure in the mold and the test voltage was among the range from -200 to $300 \mathrm{mV}$.

Electrochemical measurements. All electrocatalysis tests of the catalysts were performed at ambient environment on the electrochemical workstation (SP-150, Bio-Logic) in a standard three-electrode configuration in $0.5 \mathrm{M} \mathrm{KHCO}_{3}$. Carbon rod and $\mathrm{Ag} / \mathrm{AgCl}$ electrode were used as the counter and reference electrode, respectively. The experiment was performed in an airtight electrochemical H-type cell with a catalyst-modified carbon cloth electrode (denoted as CCE, $1 \mathrm{~cm} \times 2 \mathrm{~cm}$ ) as the work electrode.

Given the poor intrinsic electrical conductivity of M-TTCOFs, acetylene black was introduced to mix with M-TTCOFs to improve the conductivity. Nafion solution was introduced as a kind of electrocatalyst dispersion solution, which can form a homogeneous ink with COF and further help to attach onto the surface of carbon cloth. The preparation procedures of the CCE working electrode was presented as follows: $10 \mathrm{mg}$ electrocatalyst, $3 \mathrm{mg}$ acetylene black, and $1 \mathrm{~mL} 0.5 \%$ Nafion solution were grounded to form uniform catalyst ink. After sonication for $30 \mathrm{~min}$, the ink was dropped directly onto a carbon cloth $(1 \mathrm{~cm} \times 1 \mathrm{~cm})$ with a catalyst loading density of $\sim 1 \mathrm{mg} \mathrm{cm}^{-2}$ and dried. In the H-type cell, two compartments were separated by an exchange membrane (Nafion ${ }^{\circledR} 212$ ). We have measured the thicknesses of working electrodes before and after the deposition of COF materials using a vernier caliper (all the samples are properly seized on the vernier caliper without deformation), but there are no obviously change $(\sim 0.30 \mathrm{~mm})$ in the macroscopic range (Supplementary Fig. 42a, b). Therefore, we intend to detect the thickness of the working electrode from microscopic perspective through SEM test. For example, taking Co-TTCOF based working electrode, the average diameter of sample-coated carbon cloth is about $9.8 \mu \mathrm{m}$ compared with the bare carbon cloth $(7.8 \mu \mathrm{m})$. Based on the result, the thickness of the coating is estimated to be about $1 \mu \mathrm{m}$ (Supplementary Fig. 42c, d).

During the electrocatalytic $\mathrm{CO}_{2} \mathrm{RR}$ experiments, the polarization curves were performed by LSV mode at a scan rate of $2 \mathrm{mV} \mathrm{s}^{-1}$. Initially, polarization curves for the modified electrode were recorded under an inert $\mathrm{N}_{2}$ atmosphere. After that, the solution was bubbled with $\mathrm{CO}_{2}(99.999 \%)$ for at least $30 \mathrm{~min}$ to make the aqueous solution saturated and then the electrocatalytic $\mathrm{CO}_{2} \mathrm{RR}$ test was conducted. Potential was measured vs. $\mathrm{Ag} / \mathrm{AgCl}$ electrode and the results were reported vs. RHE based on the Nernst equation: $E$ (vs. RHE) $=E($ vs. $\mathrm{Ag} / \mathrm{AgCl})+0.1989 \mathrm{~V}+$ $0.059 \times \mathrm{pH}$

EIS spectroscopy measurement was carried out by applying an AC voltage with $10 \mathrm{mV}$ amplitude in a frequency range from $1000 \mathrm{kHz}$ to $100 \mathrm{mHz}$ at overpotential of $-0.7 \mathrm{~V}$ (vs. RHE). To estimate the ECSA, CV were tested by measuring $C_{d l}$ under the potential window range from $0.05 \mathrm{~V}$ to $0.25 \mathrm{~V}$ (vs. RHE) with various scan rates from 10 to $100 \mathrm{mV} \mathrm{s}^{-1}$. All the LSV curves were presented without $i R$ compensation.

Chemicals and materials. All solvents and reagents obtained from commercial sources were used without further purification. TTF $(\geq 98 \%)$ was purchased from J\&K China Chemical Ltd. Mesitylene $(\geq 99.5 \%)$ was purchased from Sinopharm Chemical Reagent Co., Ltd. $\mathrm{H}_{2}$-TAPP was purchased from Kaiyulin (Shanghai) Development Co., Ltd. 1, 4-Dioxane ( $\geq 99.7 \%)$ was purchased from MACKLIN reagent. 4-Bromobenzaldehyde was purchased from Meryer (Shanghai) Chemical Technology Co., Ltd. Exchange membrane (Nafion $\left.{ }^{\circledR} 212\right) \mathrm{Cs}_{2} \mathrm{CO}_{3}$ was purchased from Tokyo Chemical Industry (Shanghai) Co., Ltd. $\mathrm{CHCl}_{3}$ and $\mathrm{Na}_{2} \mathrm{SO}_{4}$ were purchased from China National Medicines Corporation Ltd.

Reaction product analysis and calculation. The electrolysis was carried out in an airtight electrochemical $\mathrm{H}$-type cell at selected potentials $(-0.5$ to $-0.9 \mathrm{~V})$ to determine the reduction products and their Faradic efficiency. The gaseous reduction products (e.g., CO) were monitored by a GC (GC-7920) equipped with a flame ionization detector. During the test, nitrogen was the carrier gas. A TCD was used to analyze hydrogen with nitrogen as the carrier gas.

The liquid products were collected from the cathode chambers after electrolysis and quantified by NMR (Bruker AVANCEAV III 400) spectroscopy, in which 0.5 $\mathrm{mL}$ electrolyte was mixed with $0.1 \mathrm{~mL} \mathrm{D}_{2} \mathrm{O}$. Solvent pre-saturation technique was implemented to suppress the water peak.

The calculation of Faradaic efficiency

For $\mathrm{CO}$,

$$
\mathrm{FE}=\frac{2 F \times n_{\mathrm{co}}}{i \times t} \times 100 \%
$$

For $\mathrm{H}_{2}$,

$$
\mathrm{FE}=\frac{2 F \times n_{\mathrm{H}_{2}}}{i \times t} \times 100 \%
$$

where $\mathrm{F}$ is the Faraday constant, $n_{\mathrm{CO}}$ is the moles of produced $\mathrm{CO}, t$ is the time (s), and $n_{\mathrm{H}_{2}}$ is the moles of produced $\mathrm{H}_{2}$. 
Turnover frequency (TOF, $\mathrm{s}^{-1}$ )

The TOF for $\mathrm{CO}$ was calculated as follows:

$$
\mathrm{TOF}=\frac{i \times E_{\mathrm{F}}}{N \times F \times n_{\text {tot }}}
$$

The TON for $\mathrm{CO}$ was calculated as follows:

$$
\mathrm{TON}=\frac{Q \times E_{\mathrm{F}}}{N \times F \times n_{\text {tot }}}
$$

where $Q$ is the total charge passed in time, $i$ is the current, $E_{\mathrm{F}}$ is the Faradaic efficiency for the desired product, $N$ is the number of electrons in the half reaction $\left(N=2\right.$ for $\mathrm{CO}_{2}$ to $\mathrm{CO}$ conversion), $F$ is the Faraday constant $\left(F=96485 \mathrm{C} \mathrm{mol}^{-1}\right.$ electrons), and $n_{\text {tot }}$ is the total moles of catalyst employed in the electrolysis. The TON is calculated on the basis of the actually catalytic activity.

Regression of the linear regime between 20 and $120 \mathrm{mV} \mathrm{s}^{-1}$ with equation gives the surface concentrations:

$$
\text { Slope }=\frac{n^{2} F^{2} A \tau_{0}}{4 R T}
$$

where $\tau_{0}$ is the surface concentrations, $n$ is number of electrons involved, $R$ is gas constant, and $T$ is temperature $(298 \mathrm{~K})$

\section{Data availability}

The data that support the findings of this study are available from the corresponding author upon reasonable request. The source data underlying Figs. 1b-e, 1g, 2a-f, 3a-e, and $4 \mathrm{a}-\mathrm{b}$ are provided as a Source Data file.

Received: 9 August 2019; Accepted: 11 December 2019;

Published online: 24 January 2020

\section{References}

1. Marques Mota, F. \& Kim, D. H. From $\mathrm{CO}_{2}$ methanation to ambitious longchain hydrocarbons: alternative fuels paving the path to sustainability. Chem. Soc. Rev. 48, 205-259 (2019).

2. Jacobson, T. A. et al. Direct human health risks of increased atmospheric carbon dioxide. Nat. Sustain. 2, 691-701 (2019).

3. Wang, Y.-R. et al. Oriented electron transmission in polyoxometalatemetalloporphyrin organic framework for highly selective electroreduction of $\mathrm{CO}_{2}$. Nat. Commun. 9, 4466 (2018).

4. Chen, E.-X. et al. Acid and base resistant zirconium polyphenolatemetalloporphyrin scaffolds for efficient $\mathrm{CO}_{2}$ photoreduction. Adv. Mater. 30, 1704388 (2018).

5. Kattel, S., Liu, P. \& Chen, J. G. Tuning selectivity of $\mathrm{CO}_{2}$ hydrogenation reactions at the metal/oxide interface. J. Am. Chem. Soc. 139, 9739-9754 (2017).

6. Haegel, N. M. et al. Terawatt-scale photovoltaics: trajectories and challenges. Science 356, 141-143 (2017).

7. Wu, J., Huang, Y., Ye, W. \& Li, Y. $\mathrm{CO}_{2}$ reduction: from the electrochemical to photochemical approach. Adv. Sci. 4, 1700194 (2017).

8. Jiao, Y., Zheng, Y., Jaroniec, M. \& Qiao, S. Z. Design of electrocatalysts for oxygen- and hydrogen-involving energy conversion reactions. Chem. Soc. Rev. 44, 2060-2086 (2015).

9. Qiao, J., Liu, Y., Hong, F. \& Zhang, J. A review of catalysts for the electroreduction of carbon dioxide to produce low-carbon fuels. Chem. Soc. Rev. 43, 631-675 (2014).

10. Zhu, D. D., Liu, J. L. \& Qiao, S. Z. Recent advances in inorganic heterogeneous electrocatalysts for reduction of carbon dioxide. Adv. Mater. 28, 3423-3452 (2016).

11. Luc, W. et al. Two-dimensional copper nanosheets for electrochemical reduction of carbon monoxide to acetate. Nat. Catal. 2, 423-430 (2019).

12. Gu, J., Hsu, C.-S., Bai, L., Chen, H. M. \& Hu, X. Atomically dispersed Fe ${ }^{3+}$ sites catalyze efficient $\mathrm{CO}_{2}$ electroreduction to CO. Science 364, 1091 (2019).

13. Asadi, M. et al. Nanostructured transition metal dichalcogenide electrocatalysts for $\mathrm{CO}_{2}$ reduction in ionic liquid. Science 353, 467 (2016).

14. Guo, S. et al. A $\mathrm{Co}_{3} \mathrm{O}_{4}-\mathrm{CDots}-\mathrm{C}_{3} \mathrm{~N}_{4}$ three component electrocatalyst design concept for efficient and tunable $\mathrm{CO}_{2}$ reduction to syngas. Nat. Commun. 8, 1828 (2017).

15. Jung, $\mathrm{H}$. et al. Electrochemical fragmentation of $\mathrm{Cu}_{2} \mathrm{O}$ nanoparticles enhancing selective $\mathrm{C}-\mathrm{C}$ coupling from $\mathrm{CO}_{2}$ reduction reaction. J. Am. Chem. Soc. 141, 4624-4633 (2019).

16. Li, F., Chen, L., Knowles, G. P., MacFarlane, D. R. \& Zhang, J. Hierarchical mesoporous $\mathrm{SnO}_{2}$ nanosheets on carbon cloth: a robust and flexible electrocatalyst for $\mathrm{CO}_{2}$ reduction with high efficiency and selectivity. Angew. Chem. Int. Ed. 56, 505-509 (2017).
17. Lin, S. et al. Covalent organic frameworks comprising cobalt porphyrins for catalytic $\mathrm{CO}_{2}$ reduction in water. Science 349, 1208 (2015).

18. Diercks, C. S. et al. Reticular electronic tuning of porphyrin active sites in covalent organic frameworks for electrocatalytic carbon dioxide reduction. J. Am. Chem. Soc. 140, 1116-1122 (2018).

19. Liu, H. et al. Covalent organic frameworks linked by amine bonding for concerted electrochemical reduction of $\mathrm{CO}_{2}$. Chem 4, 1696-1709 (2018).

20. Côté, A. P. et al. Porous, crystalline, covalent organic frameworks. Science 310 , 1166 (2005)

21. Jiang, D. et al. Covalent organic frameworks: chemical approaches to designer structures and built-in functions. Angew. Chem. Int. Ed. 58, 16217-1622 (2019).

22. Ding, H. et al. An AIEgen-based 3D covalent organic framework for white light-emitting diodes. Nat. Commun. 9, 5234 (2018).

23. Cai, S.-L. et al. Tunable electrical conductivity in oriented thin films of tetrathiafulvalene-based covalent organic framework. Chem. Sci. 5, 4693-4700 (2014).

24. Lei, Z. et al. Boosting lithium storage in covalent organic framework via activation of 14-electron redox chemistry. Nat. Commun. 9, 576 (2018).

25. Wang, S. et al. Exfoliation of covalent organic frameworks into few-layer redox-active nanosheets as cathode materials for lithium-ion batteries. J. Am. Chem. Soc. 139, 4258-4261 (2017).

26. Chen, $X$. et al. High-lithium-affinity chemically exfoliated $2 \mathrm{D}$ covalent organic frameworks. Adv. Mater. 31, 1901640 (2019).

27. Bunck, D. N. \& Dichtel, W. R. Bulk synthesis of exfoliated two-dimensional polymers using hydrazone-linked covalent organic frameworks. J. Am. Chem. Soc. 135, 14952-14955 (2013).

28. Chandra, S. et al. Chemically stable multilayered covalent organic nanosheets from covalent organic frameworks via mechanical delamination. J. Am. Chem. Soc. 135, 17853-17861 (2013).

29. Narayan, T. C., Miyakai, T., Seki, S. \& Dincă, M. High charge mobility in a tetrathiafulvalene-based microporous metal-organic framework. J. Am. Chem. Soc. 134, 12932-12935 (2012)

30. Jana, A. et al. Functionalised tetrathiafulvalene- (TTF-) macrocycles: recent trends in applied supramolecular chemistry. Chem. Soc. Rev. 47, 5614-5645 (2018).

31. Dong, W.-l et al. Substrate orientation effect in the on-surface synthesis of tetrathiafulvalene-integrated single-layer covalent organic frameworks. Langmuir 31, 11755-11759 (2015).

32. Wan, S. et al. Covalent organic frameworks with high charge carrier mobility Chem. Mater. 23, 4094-4097 (2011).

33. Lu, M. et al. Rational design of crystalline covalent organic frameworks for efficient $\mathrm{CO}_{2}$ photoreduction with $\mathrm{H}_{2} \mathrm{O}$. Angew. Chem. Int. Ed. 58, 12392-12397 (2019)

34. Lin, G. et al. 3D porphyrin-based covalent organic frameworks. J. Am. Chem. Soc. 139, 8705-8709 (2017).

35. Ding, $H$. et al. A tetrathiafulvalene-based electroactive covalent organic framework. Chem. Eur. J. 20, 14614-14618 (2014).

36. Chen, R. et al. Designed synthesis of a $2 \mathrm{D}$ porphyrin-based $\mathrm{sp}^{2}$ carbonconjugated covalent organic framework for heterogeneous photocatalysis. Angew. Chem. Int. Ed. 58, 6430-6434 (2019).

37. Biswal, B. P. et al. Nonlinear optical switching in regioregular porphyrin covalent organic frameworks. Angew. Chem. Int. Ed. 58, 6896-6900 (2019).

38. Bhunia, S. et al. Electrochemical stimuli-driven facile metal-free hydrogen evolution from pyrene-porphyrin-based crystalline covalent organic framework. ACS Appl. Mater. Interfaces 9, 23843-23851 (2017).

39. Brownbill, N. J. et al. Structural elucidation of amorphous photocatalytic polymers from dynamic nuclear polarization enhanced solid state NMR. Macromolecules 51, 3088-3096 (2018).

40. Patra, B. C. et al. A metal-free covalent organic polymer for electrocatalytic hydrogen evolution. ACS Catal. 7, 6120-6127 (2017).

41. Bhunia, S. et al. Efficacious electrochemical oxygen evolution from a novel Co (II) porphyrin/pyrene-based conjugated microporous polymer. ACS Appl. Mater. Interfaces 11, 1520-1528 (2019).

42. Hernan, L. et al. Diffraction and XPS studies of misfit layer chalcogenides intercalated with cobaltocene. Chem. Mater. 7, 1576-1582 (1995).

43. Guo, J. et al. Conjugated organic framework with three-dimensionally ordered stable structure and delocalized $\pi$ clouds. Nat. Commun. 4, 2736 (2013).

44. Dogru, M. et al. A photoconductive thienothiophene-based covalent organic framework showing charge transfer towards included fullerene. Angew. Chem. Int. Ed. 52, 2920-2924 (2013).

45. Guan, X. et al. Chemically stable polyarylether-based covalent organic frameworks. Nat. Chem. 11, 587-594 (2019).

46. $\mathrm{Wu}, \mathrm{Y}$. et al. Electron density modulation of $\mathrm{NiCo}_{2} \mathrm{~S}_{4}$ nanowires by nitrogen incorporation for highly efficient hydrogen evolution catalysis. Nat. Commun. 9, 1425 (2018).

47. Birdja, Y. Y. et al. Advances and challenges in understanding the electrocatalytic conversion of carbon dioxide to fuels. Nat. Energy 4, 732-745 (2019). 
48. Jin, S. et al. Two-dimensional tetrathiafulvalene covalent organic frameworks: towards latticed conductive organic salts. Chem. Eur. J. 20, 14608-14613 (2014).

49. Mitamura, Y., Yorimitsu, H., Oshima, K. \& Osuka, A. Straightforward access to aryl-substituted tetrathiafulvalenes by palladium-catalysed direct C-H arylation and their photophysical and electrochemical properties. Chem. Sci. 2, 2017-2021 (2011).

\section{Acknowledgements}

This work was financially supported by NSFC (Numbers 21622104, 21701085, 21871141, and 21871142); the NSF of Jiangsu Province of China (Number BK20171032); the Natural Science Research of Jiangsu Higher Education Institutions of China (Number 17KJB150025); Priority Academic Program Development of Jiangsu Higher Education Institutions and the Foundation of Jiangsu Collaborative Innovation Center of Biomedical Functional Materials.

\section{Author contributions}

Y.-Q.L., S.-L.L., H.-J.Z., and M.L. conceived the idea. H.-J.Z., M.L., J.L., and Y.C. designed the experiments, collected, and analyzed the data. Y.-R.W. and M.Z. assisted with the experiments and characterizations. S.-J.Y. and Y.-H.K. accomplished the theoretical calculation. H.-J.Z. wrote the manuscript. All authors discussed the results and commented on the manuscript.

\section{Competing interests}

The authors declare no competing interests.

\section{Additional information}

Supplementary information is available for this paper at https://doi.org/10.1038/s41467019-14237-4.

Correspondence and requests for materials should be addressed to Y.-Q.L.

Peer review information Nature Communications thanks the anonymous reviewer(s) for their contribution to the peer review of this work. Peer reviewer reports are available.

Reprints and permission information is available at http://www.nature.com/reprints

Publisher's note Springer Nature remains neutral with regard to jurisdictional claims in published maps and institutional affiliations.

(c) (i) Open Access This article is licensed under a Creative Commons Attribution 4.0 International License, which permits use, sharing adaptation, distribution and reproduction in any medium or format, as long as you give appropriate credit to the original author(s) and the source, provide a link to the Creative Commons license, and indicate if changes were made. The images or other third party material in this article are included in the article's Creative Commons license, unless indicated otherwise in a credit line to the material. If material is not included in the article's Creative Commons license and your intended use is not permitted by statutory regulation or exceeds the permitted use, you will need to obtain permission directly from the copyright holder. To view a copy of this license, visit http://creativecommons.org/ licenses/by/4.0/.

(C) The Author(s) 2020 